\title{
Progressive renal failure complicated by transient and recurrent ureteral obstruction
}

\author{
Alexandre P. Garneau MSc, Paul René de Cotret MD, Maude Tesolin MD, Paul Isenring MD PhD
}

口 Cite as: CMAJ 2018 October 1;190:E1168-70. doi: 10.1503/cmaj.180514

A

76-year-old woman was admitted to hospital with severe renal failure, extracellular fluid volume expansion and high blood pressure. For two days, the patient had produced no urine and had left flank pain that radiated to her groin. Over the preceding two years, the patient's serum creatinine had risen from 75 to $125 \mu \mathrm{mol} / \mathrm{L}$ (one year earlier), and again to $165 \mu \mathrm{mol} / \mathrm{L}$ (four months earlier). In addition, she had a history of refractory hypertension and severe peripheral arterial disease. She thus appeared to have acute ureteral obstruction superimposed on chronic progressive renal failure.

On arrival to hospital, the patient had an empty bladder and a serum creatinine of $520 \mu \mathrm{mol} / \mathrm{L}$. Doppler ultrasonography showed her right kidney to be severely atrophied, with severe occlusion of the left renal artery at the ostium and distal obstruction of the left ureter with no urolithiasis. A nuclear renogram showed that her right kidney was nonfunctional. After she was admitted, her serum creatinine decreased spontaneously to $150 \mu \mathrm{mol} / \mathrm{L}$ within five days and was accompanied by intense polyuria. In the two weeks that followed, she had two additional episodes of abrupt anuria; the second episode was managed by percutaneous nephrostomy. Subsequently, serum creatinine rapidly decreased to $150 \mu \mathrm{M}$, with no recurrence of the ureteral obstruction.

\section{KEY POINTS}

- Ureterosciatic herniation is an uncommon cause of acute ureteral obstruction.

- Atrophy of the piriformis muscle as a result of hip joint disease is one of the main predisposing factors for this type of hernia.

- Because atrophy of the piriformis is a common finding on imaging, ureterosciatic herniation could be more prevalent than is currently appreciated.

- In older patients, acute renal failure should be investigated with a thorough radiologic workup and with the premise that there could be more than one cause.

A retrograde pyelogram done during the patient's stay in hospital was inconclusive owing to suboptimal opacification. Three abdominopelvic computed tomography (CT) images were inconclusive. On further review, however, some of the cross-sectional CT images showed the distal left ureter engaged in the suprapiriformis foramen of the greater sciatic notch (Figure 1). In addition, the piriformis muscle was atrophied ipsilaterally, and the neighbouring hip joint showed mild degenerative changes. We

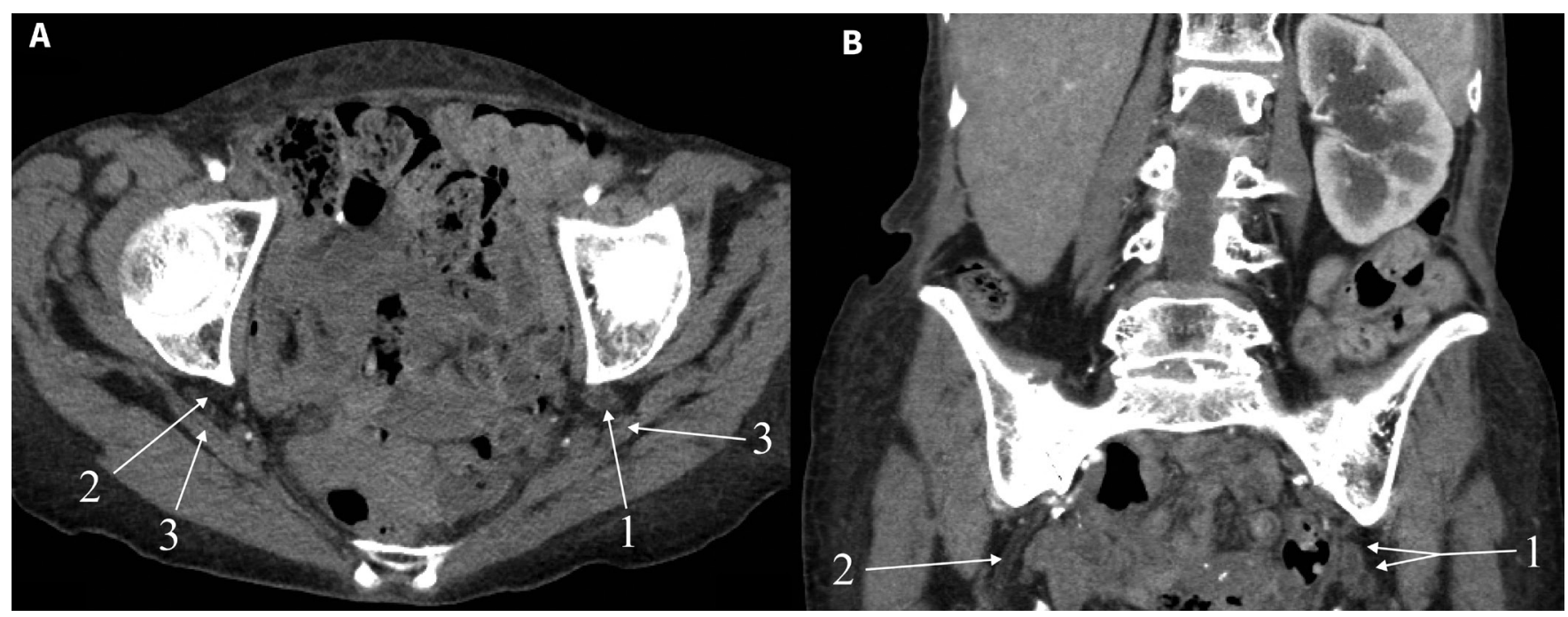

Figure 1: (A) Transverse and (B) coronal views of abdominopelvic computed tomography images with contrast enhancement in a 76-year-old woman with renal failure. Note the dilated ureter protruding into the suprapiriformis compartment of the greater sciatic notch (1) and the appearance of this compartment in the absence of the ureter (2). The piriformis muscle (3) can be seen. 
concluded the three episodes of obstruction to be the result of transient ureterosciatic herniation, hence our decision to undertake a nephrostomy.

For several days after the nephrostomy, the patient continued to have hypertension, and her serum creatinine did not decrease below $150 \mu \mathrm{M}$. For these reasons, and because the ultrasonographic data were consistent with left renovascular disease in the absence of substantial post-stenotic atrophy, we revascularized the left renal artery intraluminally after angiography to confirm occlusion at the ostium. After this second procedure, serum creatinine decreased to $100 \mu \mathrm{mol} / \mathrm{L}$, and the patient's blood pressure was controlled. We concluded that renovascular disease was the cause of progressive decline in kidney function and the poor response to antihypertensive therapy.

\section{Discussion}

This patient had both acute ureteral obstruction and advanced, clinically consequential atherosclerotic renal disease. Her case proved challenging because she had two disorders that affected her left kidney function, and her ureterosciatic hernia was not initially recognized.

In older women, acute urinary tract obstruction is often associated with preexisting renal failure of various causes and is commonly due to calculous disease, bladder dysfunction or neoplasms of the urogenital system. ${ }^{1}$ With extrinsic obstruction, cancer is the most likely cause, but additional possibilities exist, and the ureteral anatomy can be the key to identifying the problem. As can be seen in Figure 2, the ureter has a long and sinuous course from kidney to bladder. In the

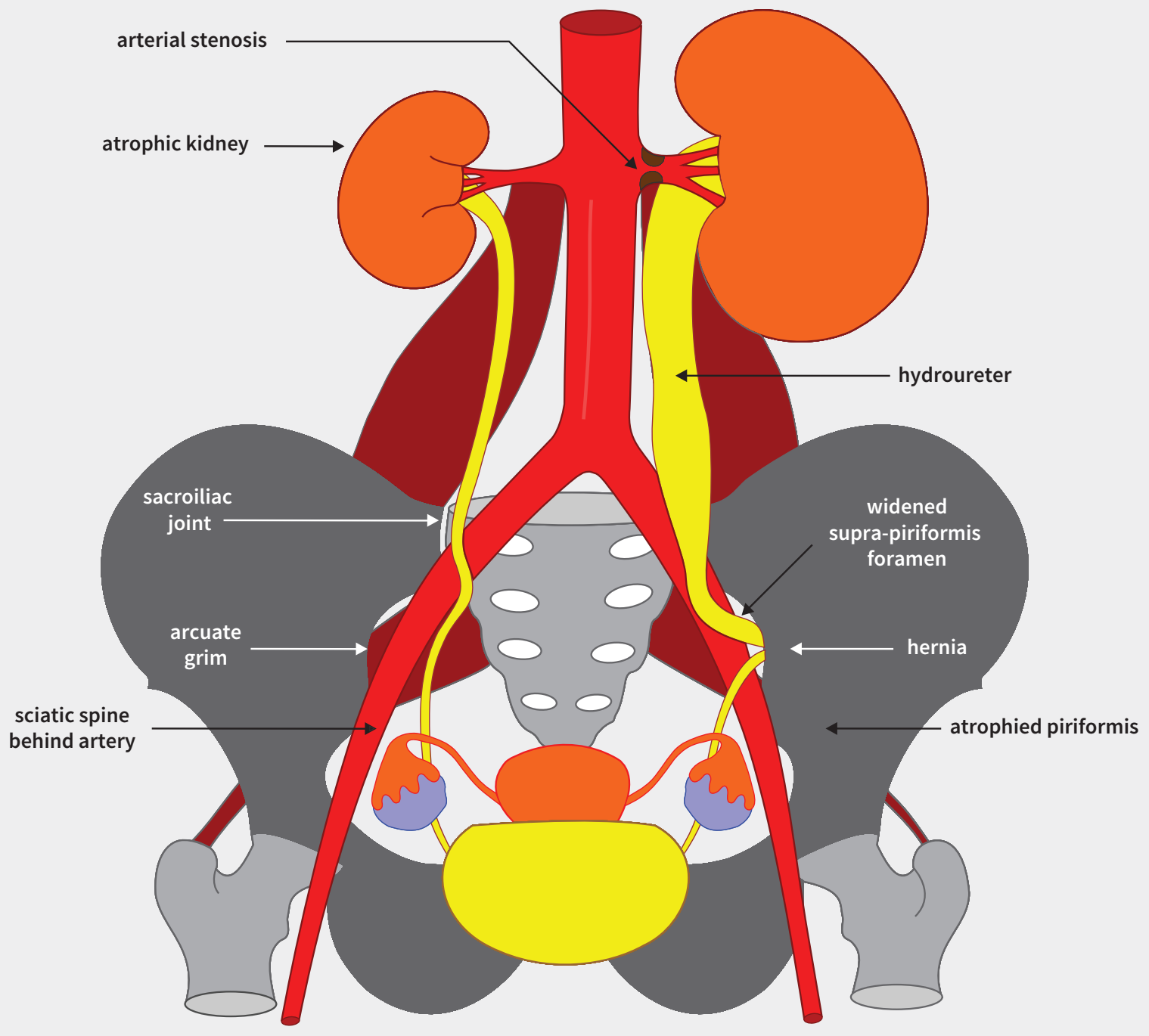

Figure 2: Illustration showing the ureteral anatomy of the patient. On the right side, the ureter is seen to travel a normal course. However, the ipsilateral kidney was severely atrophied and nonfunctional. On the left side, the ureter protrudes into the suprapiriformis compartment, where it is severely obstructed, and is dilated upstream of this location. Imaging showed that the left proximal renal artery was critically stenosed. The arcuate grim is an anatomic line that delineates the greater sciatic notch. Illustration by Paul Isenring. 
abdomen, it descends along the anterior surface of the psoas major until it reaches the bifurcation of the common iliac artery next to the inferior sacroiliac joint at the arcuate grim. In the pelvis, the ureter descends laterally $3 \mathrm{~cm}$ away of the suprapiriformis foramen, after which it reaches the ischial spine, where it turns anteromedially toward the vesical dome. In women, the pelvic ureter runs less than $1 \mathrm{~cm}$ behind the ovary and $2 \mathrm{~cm}$ next to the uterine cervix.

Our patient's ureter could have thus been compressed as a result of various lesions, such as tumours or cysts at the bladder, cervix and ovary. ${ }^{1}$ However, some types of extrinsic ureteral obstruction are less common, do not involve a common anatomic location and may be obscured by confounding comorbidities.

The suprapiriformis compartment behind the greater sciatic notch is an uncommon site of potential compression. For obstruction of the ureter to occur, the ureter must be inserted into this compartment, hence the term ureterosciatic herniation (Figure 2), which may be why there are only about 30 such reported cases. $^{2-7}$ This condition often manifests with intermittent flank plain and renal failure. Atrophy of the piriformis muscle resulting from hip joint disease is a predisposing factor, because it results in widening of the suprapiriformis foramen ${ }^{7}$ and, as seen with this patient, is not necessarily associated with symptoms in the absence of herniation.

Our patient's case highlights the importance of investigating obstructive kidney disease with a comprehensive radiologic investigation and reassessing images if the patient's condition does not resolve. If the cause is not identified using ultrasonography and plain CT imaging, delayed CT urography may provide a more precise and global visualization of the ureteral course. ${ }^{8}$ In addition, this patient's presentation shows the need to consider more than one pathology. ${ }^{9}$

As for other uncommon diseases, ${ }^{10}$ ureterosciatic herniation may be more prevalent than currently appreciated and occur in the absence of clinical manifestation. Atrophy of the piriformis muscle is a common finding on $\mathrm{CT}$ or magnetic resonance imaging in older adults, ${ }^{11,12}$ and progressive or low-grade ureteral obstruction usually has no symptoms. Thus, chronic kidney disease of unknown cause may be due to recurrent or prolonged ureterosciatic herniation in some patients.

\section{Management of ureterosciatic hernia}

The definitive treatment for ureterosciatic hernia is surgical reconstruction of the ureter by excising the herniated segment and reanastomosing the proximal ureteral end to the distal end or to the bladder directly. ${ }^{2-5}$ Another approach is to reduce the herniated segment and to prevent reherniation by fixing the ureter to the pelvic cavity or applying a mesh along the suprapiriformis foramen. ${ }^{2-5}$

Temporary treatment options are available for patients who are not candidates for surgery. ${ }^{2-5}$ The herniated segment can be reduced through a retrograde approach and made rigid with stents. This option has been successful for some patients, but it requires close follow-up. ${ }^{2-5}$

\section{References}

1. Frøkiaer J. Urinary tract obstruction. In: Brenner \& Rector's The Kidney. 10th ed. Philadelphia: Elsevier/Saunders; 2015:1257-82.

2. Clemens AJ, Thiel DD, Broderick GA. Ureterosciatic hernia. J Urol 2010; 184:1494-5.

3. Hsu HL, Huang $\mathrm{KH}$, Chang $\mathrm{CC}$, et al. Hydronephrosis caused by ureterosciatic herniation. Urology 2010;76:1375-6.

4. Ritschel S, Heimbach D, Schoeneich G. Ureterosciatic hernia. Scand J Urol Nephrol 1996;30:423-4.

5. Rommel FM, Boline GB, Huffnagle HW. Ureterosciatic hernia: an anatomical radiographic correlation. J Urol 1993;150:1232-4.

6. Spring DB, Vandeman F, Watson RA. Computed tomographic demonstration of ureterosciatic hernia. AJR Am J Roentgenol 1983;141:579-80.

7. Whyburn JJ, Alizadeh A. Acute renal failure caused by bilateral ureteral herniation through the sciatic foramen. Urology 2013;81:e38-9.

8. Dane B, Baxter AB, Bernstein MP. Imaging genitourinary trauma. Radiol Clin North Am 2017;55:321-35.

9. Tinetti ME, Bogardus ST Jr, Agostini JV. Potential pitfalls of disease-specific guidelines for patients with multiple conditions. N Engl J Med 2004;351:2870-4.

10. Mazzucato M, Visona Dalla Pozza L, Manea S, et al. A population-based registry as a source of health indicators for rare diseases: the ten-year experience of the Veneto Region's rare diseases registry. Orphanet J Rare Dis 2014;9:37.

11. Grimaldi A, Richardson C, Stanton W, et al. The association between degenerative hip joint pathology and size of the gluteus medius, gluteus minimus and piriformis muscles. Man Ther 2009;14:605-10.

12. Skorupska E, Keczmer P, Lochowski RM, et al. Reliability of MR-based volumetric 3-D analysis of pelvic muscles among subjects with low back with leg pain and healthy volunteers. PLoS One 2016;11:e0159587.

\section{Competing interests: None declared.}

This article has been peer reviewed.

The authors have obtained patient consent.

Affiliations: Nephrology Center (Garneau, Isenring, de Cotret); Departments of Radiology of the L'Hôtel-Dieu de Québec Hospital and Medicine (Tesolin), Faculty of Medicine, Laval University, Québec, Que.; Cardiometabolic Research Group (Garneau), Department of Kinesiology, University of Montreal, Montréal, Que.
Contributors: All of the authors made substantial contributions to the conception or design of the work or to the acquisition, analysis, or interpretation of data for the work; drafted the work and revised it critically for important intellectual content; approved the final version to be published; and agreed to be accountable for all aspects of the work in ensuring that questions related to the accuracy or integrity of any part of the work are appropriately investigated and resolved.
Funding: Alexandre Garneau holds a scholarship from the Canadian Institutes for Health Research (CIHR). Paul Isenring holds a CIHR Chair in Molecular Physiology; his research is funded by CIHR and the Kidney Foundation of Canada.

Correspondence to: Paul Isenring, paul.isenring@crhdq.ulaval.ca 